\title{
Alcance del régimen de responsabilidad de los socios en las cooperativas de viviendas en Euskadi
}

\author{
Extent of the liability regime of the partners \\ in the housing cooperatives of the Basque Country \\ Gotzon Gondra Elguezabal ${ }^{1 *}$, Ander Bilbao Zorrozua ${ }^{2}$
}

${ }^{1}$ Abogado-Abokatua; Letrado asesor de la Federación de Cooperativas de Viviendas-BIZIKOOP

${ }^{2}$ Abogado-Abokatua

\begin{abstract}
Resumen: Las Cooperativas de Viviendas se han consolidado en nuestro país como un modelo válido de promoción de vivienda que permite al socio acceder a este cotizado bien ahorrándose el coste de la intervención de una promotora profesional. Sin embargo, determinadas malas prácticas en el sector, junto con algunos sonados casos de quiebra de este tipo de sociedades, han dado mala fama a esta fórmula. Mediante el presente artículo, pretende ponerse el foco sobre la mayor de las garantías para las personas socias adjudicatarias de vivienda: el régimen de responsabilidad limitada. Para ello se aborda su incidencia en distintos escenarios habituales en este tipo de sociedades: la baja del socio, el concurso de acreedores y la reclamación de defectos constructivos.
\end{abstract}

Palabras clave: Cooperativas de viviendas, Socio/a, Baja, Daños y perjuicios, Responsabilidad.

Abstract: The Housing Cooperatives have been consolidated in our country as a valid model of housing promotion that allows the partner to access this quoted holding, saving the cost of the intervention of a professional promoter. However, certain bad practices in the sector, along with some well-known cases of bankruptcy of this type of companies, have given this formula a bad name. Through this article we intend to put the focus on the safest guarantee for the partners awarded the home: the limited liability regime. For this purpose, its incidence in different habitual scenarios in this type of society is analyzed: the withdrawal of the partner, the contest of creditors and the claim of constructive defects.

Keywords: Housing Cooperatives, Partner, Leave, Damages, Responsibility.

Claves Econlit: P13, P25, K12, K13, G33

* Correspondencia a/Corresponding author: Gotzon Gondra Elguezabal. Federación de Cooperativas de Viviendas-BIZIKOOP gotzong@gmail.com

Cómo citar/How to cite: Gondra Elguezabal, Gotzon; Bilbao Zorrozua, Ander (2019). "Alcance del régimen de responsabilidad de los socios en las cooperativas de viviendas en Euskadi», Gizarte Ekonomiaren Euskal Aldizkaria/Revista Vasca de Economía Social, 16, 149-166. (https://doi.org/10.1387/reves.21217).

Recibido: 25 junio, 2019; aceptado: 12 septiembre, 2019.

ISSN 1698-7446 - elSSN 2444-3107 / (C) 2019 UPV/EHU 


\section{Introducción}

La vivienda, junto con el paro, supone uno de los principales problemas socio económicos que caracteriza a la sociedad actual. Esta necesidad básica se encuentra regulada en el artículo 47 de la Constitución española como derecho social, sin embargo, no son pocas las voces que exigen que se convierta en un derecho fundamental. Recordemos que los derechos fundamentales deben ser garantizados por los poderes públicos y su ejercicio es directamente reclamable ante los tribunales.

La problemática de la vivienda ha pasado por diferentes fases en las últimas décadas en el contexto estatal, y aún más, si cabe, en la Comunidad Autónoma del País Vasco. De ser un problema de acceso a la primera vivienda, principalmente por parte de la juventud y los colectivos desfavorecidos (una vez que se había accedido a la primera vivienda parecía que no había más trabas, para cambiar de casa por ejemplo, debido a las continuas revalorizaciones de los precios de las viviendas durante casi dos lustros), ha pasado a centrarse en un problema grave de sobreendeudamiento de las familias, y ante la pérdida de sus ingresos, a los impagos y las ejecuciones hipotecarias y los desahucios.

La proliferación de las Cooperativas de Vivienda ${ }^{1}$ guarda una íntima relación con la restricción del crédito por parte del sector financiero. Así, hace tiempo que las entidades financieras vienen contemplando la fórmula cooperativa como una forma de garantía solidaria sólida respecto del crédito promotor, llegándose a plantear este mecanismo como condición indispensable para la concesión del préstamo promotor.

Como es lógico, el referido auge conlleva un aumento del volumen de viviendas promovidas bajo régimen cooperativo en nuestra Comunidad Autónoma y, por ende, irremediablemente, el incremento también de las consultas y dudas sobre el régimen jurídico de las Cooperativas de Vivien$\mathrm{das}^{2} \mathrm{y}$, en especial, sobre el régimen de responsabilidad de los socios adjudicatarios que la conforman.

1 Fajardo García, Gemma: «Cooperativas de viviendas. Constitución y funcionamiento.» Ciriec, Valencia 2014.

Gondra Elgezabal, Gotzon: "Euskadiko Etxebizitza Kooperatibak (iruzkinak)», Gizarte Ekonomiaren Euskal Aldizkaria-Revista Vasca de Economía Social, n. ${ }^{\circ}$ 0, 2004, pp. 107-138.

2 Merino Hernández, Santiago: «Realidad de las cooperativas de viviendas en la Comunidad Autónoma del País Vasco», Gizarte Ekonomiaren Euskal Aldizkaria-Revista Vasca de Economía Social, n. ${ }^{\circ}$ 15, 2018, pp. 273-300.

Gondra Elgezabal, Gotzon: «Euskadiko Etxebizitza Kooperatibak (iruzkinak)». Gizarte Ekonomiaren Euskal Aldizkaria-Revista Vasca de Economía Social, n. ${ }^{\circ}$ 0, 2004, pp. 107-138. 
El presente artículo pretende aportar algo de claridad respecto de la posición jurídica en la que se encuentran esos miles de personas que se incorporan a cooperativas de viviendas sin tener, por lo general, el más mínimo conocimiento sobre el hecho cooperativo. Circunscribiéndose exclusivamente a dicho régimen de responsabilidad, obviando el estudio relativo a la eventual responsabilidad de los administradores ${ }^{3}$ por superar la finalidad de este artículo. Para ello, se estima oportuno diferenciar entre la responsabilidad que se deriva de una baja, es decir, de un incumplimiento contractual, de la que podría derivarse en el marco de un proceso concursal o de una reclamación de defectos constructivos por parte de uno de los socios adjudicatarios $\mathrm{o}$, incluso, de un tercero.

\section{Consecuencias económicas derivadas de la baja e incumplimiento contractual}

De esta manera, y comenzando con la responsabilidad que podría derivarse como consecuencia de una baja en la condición de socio adjudicatario, debemos señalar que la baja puede ser voluntaria u obligatoria:

a) Voluntaria, cuando trae causa directa de la voluntad del socio de abandonar su condición de tal.

b) Obligatoria, cuando el socio pierde los requisitos establecidos para adquirir la condición de socio adjudicatario.

En cualquiera de los dos supuestos expuestos, la baja puede tener la consideración de justificada o no justificada. Aspecto que resulta trascendental desde un punto de vista económico, a la hora de la determinación de la responsabilidad del socio.

Así, la baja voluntaria resultará justificada cuando se lleve a cabo en estricto cumplimiento del plazo de preaviso estatutariamente establecido a los efectos, y que en virtud de cuanto dispone el art. 26.1 de la Ley 4/1993, de 24 de junio de Cooperativas de Euskadi (en adelante LCE) no podrá ser superior a seis meses. En su defecto, cuando los administradores ${ }^{4}$ así lo acordasen, atendiendo a las circunstancias particulares del caso o cualquier otra cuestión que estimasen pertinente, sin que vengan obligados

3 Gondra Elgezabal, Gotzon:«Administratzaileen erantzukizuna Euskadiko Gizarte Ekonomiako enpresetan: Bereziki Kooperatiba Elkarteetan». Gizarte Ekonomiaren Euskal AldizkariaRevista Vasca de Economía Social, n.o 1, 2005, pp. 119-141.

${ }^{4}$ Bilbao Zorrozua, Ander: "El limite competencial del Consejo Rector frente a la Asamblea General de Socios en las Cooperativas de Vivienda». Gizarte Ekonomiaren Euskal Aldizkaria-Revista Vasca de Economía Social, n. ${ }^{\circ}$ 11, 2014, pp. 7-23. 
a ello; es decir, quedando al total arbitrio de los administradores la toma de decisión en caso de incumplimiento del plazo de preaviso, sin perjuicio del deber de diligencia que pudiera obligar al mantenimiento de una línea de actuación uniforme para supuestos similares.

Además, también se calificarán como no justificadas las bajas que, aún cumpliendo el plazo de preaviso estatutariamente establecido, se produzcan:

- realizando el socio actividades competitivas con las de la Cooperativa, entendiéndose como tales la adquisición de otra vivienda (o elemento que estuviere promoviendo la Cooperativa) titularidad de o promovida por un tercero, distinta a aquélla de la que hubiera resultado adjudicatario;

— incumpliendo el período mínimo de permanencia que pudiera venir regulado en los propios Estatutos, que no podrá ser superior a 5 ańos, en virtud de cuanto dispone el art. 26.3 de la LCE, salvo que los administradores acordaren lo contrario atendiendo a las circunstancias del caso, o

— no atendiendo a la exigencia formulada por los administradores de permanecer hasta el final del ejercicio económico, siempre y cuando dicha posibilidad viniera expresamente regulada también en los propios Estatutos Sociales.

Por otro lado, la baja obligatoria resultará justificada cuando la pérdida de los requisitos para resultar socio adjudicatario de la Cooperativa traiga causa de motivos ajenos a la voluntad del socio, considerándose en sentido contrario no justificada cuando la referida pérdida de los requisitos sea consecuencia de la voluntad del socio de incumplir sus obligaciones para con la Cooperativa y resto de socios que la conforman.

Cualquiera que fuera el motivo que causó la baja, cuando la misma fuera calificada por los administradores como no justificada, cabrá la aplicación en todo caso de una deducción de hasta el 20\% de las aportaciones obligatorias a capital social (art. 63.1 de la LCE), y de hasta el 50\% del porcentaje que se le hubiera aplicado en aquél concepto (es decir, de hasta el $10 \%$ ) de las cantidades que hubiera podido desembolsar hasta la fecha de su efectiva baja en concepto de cantidades entregadas a cuenta para adjudicación de vivienda, siempre y cuando dicha posibilidad viniere expresamente regulada en los Estatutos Sociales (art. 115.1 de la LCE) ${ }^{5}$. Cabe aclarar en relación con lo anterior que son dos, principalmente, las aporta-

5 Merino Hernández, Santiago: «Manual de Derecho de Sociedades Cooperativas», Universidad del País Vasco-Consejo Superior de Cooperativas de Euskadi, Vitoria-Gasteiz 2008, pp. 337-354. 
ciones que una persona socia puede realizar en una cooperativa de vivienda a lo largo del proyecto promocional:

- De un lado, encontramos las aportaciones a capital social, idénticas a las que el socio realizaría en cualquier otro tipo de cooperativa de las que regula la Ley 4/1993, que constituye una de las condiciones básicas de adquisición por parte del socio de su condición de tal. Estas primeras están exentas del Impuesto sobre el valor Añadido (en adelante IVA), puesto que la legislación tributaria no considera como hecho imponible per se la aportación al capital de una sociedad.

- De otro lado, se realizarán las aportaciones a cuenta para adjudicación de vivienda, elemento propio de las cooperativas de viviendas que constituye el presupuesto básico por el que la persona socia ostenta al mismo tiempo la condición de adjudicataria de una vivienda y sus anejos. Este desembolso sí es objeto de tributación por IVA, al ir directamente destinado a la financiación de la vivienda y anejos que se adjudicarán mediante escritura pública una vez ejecutada la promoción. En este caso, la Norma Tributaria establece a la fecha un tipo reducido de IVA del $10 \%$ a la vivienda y todos los anejos directamente vinculados con la misma, como pueden ser plazas de garaje o trasteros.

Además, aún cuando escape de la finalidad del presente estudio por tratarse de una cuestión distinta, atendiendo a su derivación, no podemos obviar tampoco en relación a éstas últimas la referencia al hecho de que la Cooperativa venga obligada, en cumplimiento de cuanto dispone la legislación vigente, a avalar las referidas cantidades ${ }^{6}$. Obligación que cuenta además con el inestimable apoyo del Tribunal Supremo, que estima que cualquier interpretación de la citada obligación sobre percibo de anticipos debe hacerse a favor del consumidor - comprador-, equiparando en el caso concreto que nos ocupa al socio adjudicatario con la figura del consumidor ${ }^{7}$.

Con carácter excepcional, dispone la LCE (art. 63.1) que en el supuesto de que la baja resultare calificada como no justificada como consecuencia del incumplimiento del período mínimo de permanencia por

${ }^{6}$ Ley 20/2015, de julio, de Ordenación, Supervisión y Solvencia de las Entidades Aseguradoras y Reaseguradoras, que viene a derogar a este respecto lo dispuesto, en similar sentido, por la Ley 57/1968, de 27 de julio, sobre percibo de cantidades anticipadas en la construcción y venta de viviendas.

7 STS n. ${ }^{\circ}$ 780/2014 de 17 de diciembre de 2014. 
parte del socio, el porcentaje de deducción sobre las aportaciones obligatorias podría ampliarse, en caso de así regularse en los Estatutos Sociales, del $20 \%$ al 30\% y, consecuentemente, también cabría la ampliación de las deducciones sobre las cantidades entregadas a cuenta para adjudicación de vivienda, de hasta un 10\%, al 15\% (art. 115).

Porcentajes estos últimos (30\% sobre las aportaciones obligatorias a capital social y $15 \%$ de las cantidades entregadas a cuenta para adjudicación de vivienda) que resultan idénticos a los legalmente previstos por la LCE para el supuesto de expulsión, en el que no ahondaremos en el presente artículo por estimarse que supera la pretensión del mismo.

Además de lo expuesto, dispone también la LCE (art. 26.4) que en caso de baja voluntaria por parte del socio adjudicatario, la Cooperativa podrá exigirle el cumplimiento de las actividades y servicios cooperativos en los términos en que venía obligado. Y ello aún cuando los administradores pudieran acordar calificar aquélla baja como justificada, a pesar del referido incumplimiento, atendiendo a las circunstancias particulares del caso. Es decir, que la referida posibilidad de exigencia del cumplimiento de las actividades y servicios en los términos en que venía obligado así como, en su caso, la correspondiente indemnización de daños y perjuicios no se encuentran en caso alguno supeditadas a una eventual calificación de la baja como justificada. Aspecto que adquiere especial relevancia en el supuesto de las Cooperativas de Viviendas, por cuanto entre las obligaciones que adquiere el socio en el momento de la formalización del contrato de adjudicación, se encuentra habitualmente la de elevar a escritura pública a su favor la adjudicación de los elementos promovidos por la Cooperativa de los que resultare adjudicatario. Dicha obligación nace del doble vínculo que la persona socia establece, por un lado, con la sociedad a través del contrato de adhesión en el que se regula su incorporación a la cooperativa y a todos los acuerdos adoptados por la misma hasta la fecha, incluyendo los estatutos sociales y todos los contratos reguladores del hecho promocional y constructivo, tales como el contrato de ejecución de obra, los de arrendamiento de servicios con los miembros de la Dirección Facultativa, Letrado Asesor, etc. Y, por otro lado, el socio se vincula a un o unos elementos promocionales concretos a través de la formalización del correspondiente contrato de adjudicación, en cuyo clausulado se concretan las características básicas de la vivienda y anejos en cuestión, su precio y condiciones de pago, así como el compromiso bilateral de adjudicación. Es decir, que la Cooperativa se compromete a adjudicar al socio la vivienda $y$ anejos en un momento determinado y el socio, por su parte, se compromete a escriturarlos a su favor en ese mismo momento.

Partiendo de una interpretación extensiva de lo anteriormente expuesto, cabría valorar el deber de escrituración aún cuando el socio hubiera 
causado baja con anterioridad al momento programado para ello. Interpretación que, en todo caso, parece lógico descartar sobre la base del principio cooperativo de puerta abierta, aplicable en virtud de cuanto dispone el art. 1.1 de la LCE. Lo que no impide, tal y como ya adelantábamos y desarrollaremos más adelante, el derecho a poder reclamar la correspondiente indemnización por daños y perjuicios derivados del incumplimiento contractual.

Es importante poner el foco sobre el antedicho principio de puertas abiertas. Téngase en cuenta a estos efectos que, constituyendo el mismo una de las reglas básicas de funcionamiento en las sociedades cooperativas, adquiere mayor protagonismo, si cabe, en las cooperativas de viviendas. Y ello porque, de un lado, la inversión que la persona socia realiza en este tipo de sociedades tiene un impacto elevadísimo en su economía personal, lo que obliga a actuar de forma flexible respecto de las decisiones de los socios adjudicatarios, siempre y cuando las mismas no se adopten en contra de los intereses del colectivo. Y, de otro lado, no podemos obviar el hecho de que una parte de los consumidores que se incorporan a las promociones bajo fórmula cooperativa lo hacen porque se sienten atraídos por la vivienda en sí, independientemente del modelo de promoción.

El principio de puertas abiertas, en definitiva, se traduce en la capacidad del socio de causar baja de la cooperativa en el momento que así lo desee, siempre y cuando asuma las consecuencias económicas que se advertían en los párrafos anteriores. Se trata, en suma, de dotar a la persona socia de plena libertad de decisión en lo que se refiere a su vínculo con la sociedad y con los elementos de la promoción asignados, preservando al mismo tiempo el interés del colectivo que persiste en su voluntad de llevar a buen puerto el proyecto promocional.

Expuesto el primero de los criterios a tener en cuenta, debemos analizar a continuación el segundo de los mismos, consistente en la eventual imputación de las pérdidas que pudieran encontrarse pendientes de liquidación. Imputación que resulta independiente de los términos en lo que se hubiere calificado la baja del socio, tal y como dispone expresamente el art. 63.3 de la LCE. Así, corresponderá también el oportuno descuento de las pérdidas reflejadas en el balance de cierre del ejercicio en que se produzca la baja, ya correspondan a dicho ejercicio o provengan de otros anteriores o estén sin compensar. En todo caso, resulta fundamental matizar jurídicamente la presente cuestión, por cuanto para la aplicación del citado descuento se estima conditio sine qua non el hecho de que la Asamblea General hubiera acordado expresamente dicha posibilidad para los supuestos de eventuales bajas futuras en el momento de la adopción del acuerdo consistente en imputar las pérdidas del ejercicio a una cuenta especial para su 
amortización con cargo a futuros resultados positivos, en el plazo máximo de cinco años (art. 69.1 de la LCE). Es decir, en opinión de quienes suscriben el presente artículo no cabe interpretar como suficiente para llevar a cabo dicho descuento el simple acuerdo adoptado por la Asamblea General de imputación de las pérdidas a una cuenta especial para su amortización con cargo a futuros resultados positivos, por cuanto el mismo no lleva intrínsecamente aparejado ni la individualización de aquellas pérdidas, ni su aplicación individualizada a cada socio en caso de baja. En este sentido, no cabe pretender una interpretación extensiva del acuerdo de imputación de pérdidas a una cuenta especial para su amortización con cargo a futuros resultados positivos en contra de los intereses individuales de los socios adjudicatarios, quienes deberán ser expresamente conocedores y, por lo tanto, informados, de las consecuencias económicas que se derivan o podrían derivar del mencionado acuerdo respecto a sus intereses particulares y su responsabilidad frente a la Cooperativa. Es por ello que se estima necesario el cumplimiento del formalismo de la acreditación del conocimiento por parte del socio de las eventuales consecuencias futuras derivadas del acuerdo, lo que requiere su expresa mención en el marco del acuerdo adoptado al respecto por la Asamblea General, debidamente reflejado en el Acta resultante de aquella reunión. Acreditación del conocimiento de las eventuales consecuencias jurídico-económicas futuras que deberá incluir también el/los criterio/s para la determinación de la actividad cooperativizada (operaciones, servicios o actividades) realizada por cada uno de ellos con la cooperativa con carácter anual, de la que resultará la cuantificación de las pérdidas imputables [art. 69.2.c) de la LCE].

La no aplicación del antedicho mecanismo conllevaría la absoluta indefensión del individuo frente al colectivo, así como la erradicación de facto del principio de puertas abiertas en las cooperativas de viviendas, dado que el mismo debe sustentarse sobre el pleno conocimiento por parte de la persona socia de las consecuencias del ejercicio de aquellas libertades de las que disfruta en virtud de la LCE y los Estatutos Sociales.

Por último, nos encontramos con el concepto ya anticipado de la indemnización por daños y perjuicios. Parece más que evidente concluir el hecho de que de una eventual baja por parte del socio adjudicatario con carácter previo a la efectiva adjudicación —elevación a público- a su favor de los elementos promovidos por la Cooperativa de los que hubiera resultado adjudicatario, pueden derivarse dańos y perjuicios para los intereses de la Cooperativa y, por ende, del resto de socios adjudicatarios. Y ello, porque se quedaría aquélla, de un lado, con una menor fuente de financiación, en tanto en cuanto el socio no fuera sustituido mediante la subrogación de otra persona en su posición, viéndose previsiblemente obligada a una mayor disposición del préstamo promotor, generándose de esta manera ma- 
yores intereses, y de otro, con la obligación de buscar a una persona interesada en la adjudicación de aquellos elementos que hubieran quedado libres. Subrogación que podría producirse tiempo más tarde, quedando por tanto supeditado el precio de adjudicación futura de los elementos a los vaivenes del mercado. Es decir, hasta el punto de poder verse obligada la Cooperativa a adjudicar aquellos elementos libres como consecuencia de la baja del socio a un precio sustancialmente inferior al que en su día le fueron adjudicados al socio que hubiere causado baja y, por tanto, a renunciar a unos ingresos previstos en virtud de contrato de adjudicación formalizado a los efectos. Y todo ello, como consecuencia de un incumplimiento contractual por parte del socio adjudicatario, quien habiéndose comprometido con la Cooperativa y el resto de socios que la conforman a escriturar los elementos de los que resultó adjudicatario a un precio determinado, resuelve su vinculación de manera unilateral.

¿Quién debe asumir las consecuencias económicas derivadas de ese incumplimiento contractual? ${ }^{8} \mathrm{Si}$ bien parece evidente que no cabe trasladar dichas consecuencias económicas a los socios adjudicatarios que sí cumplen con sus obligaciones para con la Cooperativa y el resto de socios que la conforman, procediendo a escriturar a su favor los elementos de los que resultaron adjudicatarios al precio establecido en sus respectivos contratos de adjudicación, dicha cuestión se estima resuelta mediante las resoluciones contenidas tanto en el Laudo arbitral 14/2012 emitido por el Servicio Vasco de Arbitraje Cooperativo del Consejo Superior de Cooperativas de Euskadi que basa buena parte de su fundamentación en al STS de 18 de junio de 1991, como en la Sentencia n. ${ }^{\circ}$ 190/2018, dictada con fecha 23 de mayo de 2018 por el Juzgado de lo Mercantil n. ${ }^{\circ} 2$ de Bilbao. Es decir, corresponde la asunción de la responsabilidad por los daños y perjuicios ocasionados a la Cooperativa como consecuencia de la baja del socio adjudicatario, a éste.

El referido Laudo 14/2012 basaba buena parte de su fundamentación en la jurisprudencia del Tribunal Supremo, que ya en su STS de 18 de junio de 1991 aclaraba que "aquellos socios que hayan sido integrados en una correcta promoción de viviendas vienen obligados a costear, con independencia de sus aportaciones societarias, los gastos constructivos de la vivienda que fuera adjudicada, y ello por supuesto, no supone incompatibilidad o contradicción alguna con el principio de responsabilidad limitada..., máxime cuando los débitos derivados de la construcción de la vivienda adjudicada a un socio determinado no puede equipararse a las sociales propiamente dichas».

${ }^{8}$ Fajardo García, Gemma: «La responsabilidad del socio en la gestión económica de la cooperativa de viviendas desde la Jurisprudencia del Tribunal Supremo». Ciriec. Revista Jurídica de Economía Social y Cooperativa, n. ${ }^{\circ}$ 5, noviembre 1994, pp. 415-417. 
Son por tanto tres los conceptos que tienen o pueden tener afección sobre la liquidación de la vinculación societaria del socio y, consecuentemente, sobre su eventual responsabilidad: las deducciones por calificación de la baja como no justificada (o expulsión); el descuento derivado de la imputación de las pérdidas que se pudieran encontrar pendientes; y la indemnización por los dańos y perjuicios ocasionados como consecuencia de incumplimiento contractual.

\section{Régimen de responsabilidad general}

Al hilo de lo referenciado, y sin perjuicio de lo anteriormente expuesto en relación a la aplicación de deducciones, descuentos e indemnizaciones por daños y perjuicios, debemos entender que la responsabilidad de los socios por las deudas sociales se encuentra limitada a sus aportaciones (art. 56 de la LCE).

Pero, ¿qué debemos entender por sus aportaciones? Porque el art. 56 habla de aportaciones a capital social, pero no es menos cierto que respecto a las que pudieran traer causa de la imputación de pérdidas es la propia LCE la que dispone que directamente o mediante deducciones en sus aportaciones al capital social o, en su caso, en cualquier inversión financiera del socio en la Cooperativa que permita esta imputación [art. 69 2.c).1.]. Y parece lógico, en opinión de quienes suscriben, considerar las cantidades entregadas a cuenta para adjudicación de vivienda desembolsadas por los socios como una pseudo inversión financiera y, por lo tanto, la posibilidad de su imputación con cargo a aquellos desembolsos.

Es decir, se estima por tanto oportuno concluir también que fruto de la aplicación de los conceptos anteriormente descritos, cabe la posibilidad de que el socio pierda todas las cantidades desembolsadas a favor de la Cooperativa en caso de baja e incumplimiento contractual del que se derivasen consecuencias económicas (incluido el referido concepto de daños y perjuicios) en cuantía idéntica o superior a aquéllas?

En este mismo sentido, cierto es también que el Decreto 58/2005, de 29 de marzo, por el que se aprueba el Reglamento de la Ley de Cooperativas de Euskadi establece en su art. 12.2 que las pérdidas asumidas y no compensadas serán consideradas como un crédito a favor de la cooperativa que podrá ser ejercitado aunque el socio haya causado baja voluntaria u obligatoria en la cooperativa.

9 Gadea Soler, Enrique: "Alcance de la responsabilidad de los socios de una cooperativa de vivienda, anotación de la sentencia del Tribunal Supremo de 12 de diciembre de 2011 », Revista Cooperativismo e economía social, n. ${ }^{\circ}$ 37, Año 2014-2015, pp. 307-316. 
Interpretación que, en la práctica, podría acabar convirtiendo en inviable el modelo de promoción de vivienda bajo fórmula cooperativa, al menos en lo que se refiere a la vivienda colectiva. Piénsese, si no, cuál sería la capacidad de captación para un proyecto de promoción en el que aquellas personas que se incorporasen al mismo debieran asumir, no solo la posibilidad de perder el capital total invertido, sino también el riesgo empresarial de la promoción de vivienda en un mercado tan fluctuante y hostil. Riesgo extensible, por tanto, a su patrimonio personal.

Otra consecuencia de dicha interpretación, íntimamente ligada con la anterior, podría ser incluso la imposibilidad de que las Cooperativas de Viviendas, ni de ninguna otra clase, pudieran instar un procedimiento concursal, como veremos a continuación.

Es por ello que se estima que en caso alguno puede el presente precepto implicar una superación del régimen legal de responsabilidad limitada dispuesto por la LCE. Límite que parece compartirse también por otras regulaciones autonómicas. ${ }^{10}$

\section{Responsabilidad en procedimiento concursal}

A partir del 2008 explotó en el Estado una crisis cuyo epicentro se generó a muchos kilómetros de distancia de las fronteras españolas, estando al mismo tiempo relacionado con uno de los sectores clave de su economía: el sector inmobiliario. Aunque esta crisis no tuvo pleno reflejo en Euskadi hasta principios del año 2010, lo cierto es que sus efectos comenzaron a notarse ya desde el 2008. En lo que se refiere al particular ámbito de las cooperativas de viviendas, destacó la caída en dominó de una serie de gestoras de cooperativas, dejando a los socios desamparados, sin rumbo, muchas veces con las obras a medio ejecutar.

Se trató de un escenario sumamente grave, en el que, mientras estas cooperativas dejaban de ejecutar el proyecto para el que habían sido constituidas — su objeto social—, dejando frustrada la expectativa de sus socios que ya habían desembolsado importantes sumas de dinero, los que habían sido proveedores de la sociedad, así como las instituciones intervinientes de un modo u otro en el proceso promotor, veían como sus créditos no eran satisfechos. Obviamente, el impago de las deudas sumado al paso del tiempo, hacía que las primeras se multiplicaran sin que las cooperativas tuvieran ningún modo de generar ingresos, al haber detenido su actividad.

10 Fernández García Lorenzana, I: «Responsabilidad del socio frente a las deudas sociales originadas como consecuencia de la actividad promocional en las sociedades cooperativas de viviendas», Revista Viviendas cooperativas (CONCOVI), n.o 51, 2000, pp. 31-33. 
Destacó en Bizkaia el caso Iurbenor que era la promotora inmobiliaria impulsada por Iurbentia y Fonorte (ambas sociedades del Grupo Afer) para el desarrollo del proyecto urbanístico Puerta Bilbao, asentado sobre los antiguos terrenos de Sefanitro en Barakaldo (Bizkaia), en los que se pretendía levantar 2.000 viviendas. Por diversos motivos, algunas de las Cooperativas que se constituyeron para promover en el referido ámbito se vieron obligadas a solicitar la declaración de concurso de acreedores.

En una de ellas (Procedimiento Concursal abreviado 74/2017-D seguido ante el Juzgado de lo Mercantil n. ${ }^{\circ} 1$ de Bilbao) el administrador concursal planteaba en su escrito de calificación del concurso como fortuito que la situación concursal se había producido, entre otros factores, por «el retraso de la ejecución de las obras como consecuencia de la descontaminación del suelo y la impugnación por la asociación de vecinos de Lutxana del plan parcial; asi como la declaración de concurso de acreedores de varias empresas que se encargaban de la gestión de la Cooperativa dejando a esta a la deriva, siendo su posterior consecuencia la baja masiva de socios que resulto trascendente, y todo en consonancia con la situación de crisis generalizada de la sociedad existente en esas fechas (...)" Esta calificación fue posteriormente confirmada por el Ministerio Fiscal, lo que llevó al archivo de la pieza de calificación mediante el Auto del 4 de junio de 2018 del Juzgado de lo Mercantil.o 1 de Bilbao, permitiendo mantener intacto el patrimonio personal de los socios de la Cooperativa concursada.

Pues bien, más allá del contexto propio y específico de la crisis financiera y su directa afección al ámbito particular de las cooperativas de viviendas - el inmobiliario - no podemos ser ajenos al hecho de que el supuesto más habitual por el que una Sociedad requiere de la incoación de un procedimiento concursal es por la acumulación de resultados negativos - pérdidas - que conlleva un patrimonio neto negativo.

Procedimiento concursal que, en la práctica, tiene como objetivo la delimitación de la responsabilidad de los administradores (sección sexta del procedimiento concursal) y, en su caso, del resto de socios (plan de liquidación).

Pues bien, si a dicho supuesto le aplicásemos en sentido estricto el art. 12.2 del Decreto 58/2005, es decir, el del crédito a favor de la Cooperativa de las pérdidas acumuladas y no compensadas, en las Cooperativas podría no tener sentido alguno la incoación de dicho procedimiento de declaración de concurso voluntario, por cuanto podría corresponder a los socios la asunción de la responsabilidad ilimitada hasta la compensación de todas las pérdidas acumuladas y pendientes de liquidación. ¿Para qué instar un procedimiento - el concursal-, regulado por el legislador como garantía de la limitación de la responsabilidad empresarial en el ám- 
bito del libre mercado, si tu responsabilidad como socio puede convertirse en ilimitada?

Parece una incongruencia, y en tal sentido debemos interpretar resoluciones judiciales como el Auto n. ${ }^{o}$ 318/2016, de 18 de julio de 2016, dictado por el Juzgado de lo Mercantil n. ${ }^{\circ} 1$ de Bilbao, que resuelve declarando no sólo el carácter voluntario del concurso, sino su conclusión por falta de masa activa y extinción de la Sociedad, con cancelación de sus asientos registrales. Y todo ello en virtud de cuanto dispone el art. 176 BIS.4 de la Ley 22/2003, de 9 de julio, concursal (en adelante LC), por no apreciar el Juez el previsible ejercicio de acción de responsabilidad de terceros, entre otros. En el supuesto de que se estimase la simple posibilidad de una eventual responsabilidad ilimitada de los socios por las pérdidas que se hubieran podido acumular, el referido artículo de la LC dejaría de resultar aplicable a las Cooperativas, cuestión que parece a todas luces inadmisible, por cuanto conllevaría dejar fuera de la aplicación de la legislación vigente a un tipo societario como es el de las cooperativas; cuestión que no resulta ni tan siquiera discutible, atendiendo a la Doctrina ${ }^{11}$. Es por ello que compartimos absolutamente la interpretación seguida por el Juzgado en su Auto, en tanto que delimita la responsabilidad de los socios a cuanto dispone la LCE, haciendo posible la aplicación de la LC también a las Cooperativas en general, y a las de la clase de viviendas en particular.

En este mismo sentido resulta decididamente esclarecedor el procedimiento concursal incoado por Fagor Electrodomésticos, S.Coop. que, a la fecha de redacción de la presente, salvo error por nuestra parte, continúa en tramitación.

Consta a quienes suscriben, la resolución adoptada por la administración concursal en el referido procedimiento respecto al régimen de responsabilidad de los socios trabajadores, estableciéndose definitivamente su carácter limitado. Y ello sobre la base de que, al margen de otras consideraciones jurídicas, atendiendo a las dimensiones de la Cooperativa, los socios trabajadores resultaban más trabajadores que socios a la hora de la adopción de los acuerdos, y como trabajadores su responsabilidad no puede superar jamás a aquella derivada de sus aportaciones. Nuevamente debemos manifestar nuestra total conformidad con el criterio seguido por la administración concursal a la hora de la determinación del régimen de responsabilidad de los socios trabajadores de la Cooperativa.

11 Villafańez Pérez, Itziar: «Cooperativa y concurso. Estudio de las relaciones jurídicas con sus socios» Marcial Pons, Madrid 2014.

Suso Vidal, José María: «El concurso de la sociedad cooperativa», Tratado de Derecho de Cooperativas, Tomo II, Tirant lo Blanch, Valencia 2013, pp. 1551-1574. 
Criterio que no sólo resulta extrapolable al caso de las Cooperativas de Viviendas, sino que se estima es además más contundente si cabe, tal y como expondremos a continuación.

Los socios trabajadores de Fagor, atendiendo a las dimensiones de la empresa resultaban más trabajadores que socios, y en las Cooperativas de Viviendas no podemos obviar que los socios adjudicatarios resultan más consumidores que socios. Las Cooperativas de Viviendas, salvo excepciones en promociones de pocas viviendas, rara vez vienen promovidas por los propios socios, sino por gestoras de cooperativas o terceros agentes que se acercan al modelo precisamente procurando trasladar el régimen de responsabilidad promocional a la Cooperativa (a pesar de lo dispuesto por el art. 17 de la Ley de Ordenación de la Edificación). Así, en la práctica, los socios adjudicatarios son simples consumidores que se acercan al modelo cooperativo y adquieren la condición de socios adjudicatarios como simple medio de adquisición - compra- de una vivienda, y no como personas interesadas en desarrollar una actividad autopromocional, asumiendo el riesgo derivado de una actividad empresarial. Y como tales consumidores, debe aplicarse a los mismos los límites de responsabilidad que acompañan a cualquier consumidor; es decir, limitada en todo caso a las cantidades que hubiera desembolsado a favor de la Cooperativa, cualquiera que fuera el concepto por el que lo hubieran hecho.

Esta visión de los socios adjudicatarios de cooperativas de viviendas como meros consumidores viene determinada por la definición de persona consumidora que realiza el propio Real Decreto Legislativo 1/2007, de 16 de noviembre, por el que se aprueba el texto refundido de la Ley General para la Defensa de los Consumidores y Usuarios y otras leyes complementarias, que en su art. 3 refiere que «son consumidores o usuarios las personas fisicas que actúen con un propósito ajeno a su actividad comercial, empresarial, oficio o profesión." Igualmente aclaratoria resulta la referencia de la Directiva 93/13/CEE del Consejo, de 5 de abril de 1993, sobre las cláusulas abusivas en los contratos celebrados con consumidores, que en su art. 2 define como consumidora "a toda persona física que, en los contratos regulados por la presente Directiva, actúe con un propósito ajeno a su actividad.»

El Tribunal Supremo también opta por dicha interpretación, al haberse visto obligado a abordar este asunto en relación, entre otros, al problema de la nulidad de determinadas cláusulas incorporadas a los préstamos hipotecarios. Así se pronuncia, en su STS del 18 de junio del 2012, en la que sostiene respecto de unos socios adjudicatarios de vivienda que presentaron demanda por nulidad de parte del clausulado de su préstamo hipotecario que «la condición de socios de los actores, no constituye su actividad empresarial, pues la sociedad de la que forman parte se trata de una sociedad cooperativa de viviendas, que tiene, por tanto, por objeto satisfacer las ne- 
cesidades de vivienda de los socios. Los cooperativistas, que tienen sus propias actividades laborales o profesionales, se asocian entre si a fin de llegar a adquirir una vivienda para uso privativo en unas determinadas condiciones. Asi, por una parte, la actividad de la cooperativa no supone la actividad empresarial o profesional de los cooperativistas, que tienen sus propias ocupaciones, y por otra, la vivienda que adquieren no se integra en sistema productivo alguno, ya que los cooperativistas son los destinatarios finales de las viviendas. En consecuencia, a los efectos de la acción ejercitada en la demanda, los demandantes tienen la condición de consumidores».

Y decimos que en el caso de las Cooperativas de Viviendas resulta más claro aún si cabe, porque en el caso de las cooperativas de trabajo asociado, la continuación de la actividad acordada por la Asamblea General a pesar de las pérdidas acumuladas trae como consecuencia un eventual resultado positivo para sus socios trabajadores: la continuación en la percepción de la retribución-anticipo laboral. Mientras, en las cooperativas de viviendas el socio no obtiene beneficio alguno de la continuidad de la actividad. Sobre todo cuando dicho acuerdo se produce en el marco de las competencias de la Asamblea General, tras recibir dicho órgano la información de las cuentas anuales por parte de un agente externo, como son las Gestoras de Cooperativas. Téngase en cuenta que, en las cooperativas de viviendas, que no suelen tener trabajadores contratados, la llevanza de la contabilidad y las finanzas corre de cuenta de una Gestora contratada para el conjunto del proyecto promocional, lo que provoca que los socios, salvo supuestos excepcionales, carezcan de información sobre las cuentas sociales hasta el momento de la celebración de la Asamblea General Ordinaria durante el primer semestre del ejercicio siguiente a aquel al que hacen referencia las cuentas en cuestión.

Es por ello, por lo que una eventual aprobación de las cuentas anuales no podrá interpretarse en caso alguno como reconocimiento de deuda alguna por parte de los socios adjudicatarios, ni frente a terceros ni frente a la Cooperativa, por cuanto se trata de cuentas auditadas (deber de auditarlas en virtud de cuanto dispone el art. 117 de la LCE en tanto exista actividad promocional, que es cuando en principio deberían aflorarse los resultados de la propia actividad), y menos cuando no hay continuidad de actividad, sino acuerdo inmediato de solicitud de declaración de concurso.

Especial referencia merece, en relación al alcance de la responsabilidad de los socios adjudicatarios en las cooperativas de viviendas concursadas, el Dictamen emitido por el Consejo Superior de Cooperativas que, en respuesta a la consulta n. ${ }^{\circ} 4 / 2017$, aclaró que, si bien es cierto que en otras comunidades autónomas existen regímenes de responsabilidad ilimitada, la Ley 4/1993 asegura la responsabilidad limitada de los socios de coopera- 
tivas vascas en general y de los socios de cooperativas de viviendas en Euskadi en particular. Así mismo, recuerda en su Dictamen el CSCE «el carácter no ejecutable del patrimonio personal de los socios de las cooperativas de viviendas, asi como el carácter no embargable de las viviendas y anejos adjudicados por una cooperativa inmersa en el concurso, en tanto que, mediante la adjudicación a los socios, se convierte en un activo ajeno al patrimonio de la deudora concursada. Dicho de otro modo, que la deuda no se transmite junto con los elementos de la promoción adjudicados."

\section{Responsabilidad por defectos constructivos}

Suele ser relativamente habitual que los socios de cooperativas de viviendas tengan asumido su papel de promotores incluso con mayor intensidad de la que realmente les corresponde. Este fenómeno suele manifestarse en los procesos de reclamación de vicios ocultos en obra nueva, cuando son los propios socios los que se plantean demandar a su Cooperativa, además de algún otro de los agentes que intervienen en el proceso promotor en virtud de cuanto establece el art. 17 de la Ley 38/1999, de 5 de noviembre, de Ordenación de la Edificación, como responsable de dichos defectos constructivos (en adelante "LOE»). Otro de los supuestos habituales es aquel en el que un tercero que adquirió su vivienda, anejo o local de un socio adjudicatario, sea el que ejercite una acción de reclamación de defectos constructivos entre otras, frente a la Cooperativa.

Sin embargo, la jurisprudencia resulta bastante más benevolente con estos socios de lo que ellos mismo son. Así, el Tribunal Supremo viene defendiendo desde hace más de 30 años que las cooperativas de viviendas carecen de responsabilidad en relación con los defectos constructivos contemplados en el Código Civil y en la LOE. Y ello porque, además de reconocer su condición de meros consumidores, tal y como ya se ha expuesto anteriormente, aprecia falta de ánimo de lucro en este tipo de sociedades, dado que esta clase de cooperativas no venden las viviendas a sus socios sino que las adjudican, compensando contablemente la citada adjudicación con las cantidades entregadas a cuenta. Así lo recogen, desde las más antiguas SSTS de 2 de octubre de 1990, 4 de diciembre de 1990, 1 de octubre de 1991, 8 de mayo de 1993, 16 de junio de 1993 y 8 de noviembre de 1993 y 1 de octubre de 1991, hasta la más reciente STS 1279/2007, del 13 de diciembre de 2007:«la equiparación jurisprudencial de la figura del promotor con la del contratista exige que la obra se realice y se encamine a la venta a terceros (...) Se ha destacado que estas sociedades no venden pisos y locales comerciales a terceros con esta finalidad, sino unicamente con la de reducir los costes de la edificación en beneficio de sus asociados. Partiendo de esta 
realidad, la jurisprudencia ha afirmado que su actividad no permite incluirlas en la descripción típica que se hace del promotor, y en consecuencia tales sociedades no están sometidas a la responsabilidad derivada de tal condición. Igual de contundente resulta la Sentencia del Tribunal Supremo 602/2013, del 21 de octubre del 2013, que excluye directamente de responsabilidad a las cooperativas de viviendas dentro del ámbito de aplicación de la LOE.

Esta cuestión, que puede parecer a primera vista más relacionada con cuestiones meramente constructivas que con el régimen individual de responsabilidad de los socios, puede tener incidencia directa sobre el patrimonio de aquellos, en tanto que la condena a una cooperativa de viviendas como responsable por defectos constructivos, puede acabar produciendo una situación en la que los socios, por desconocimiento, acuerden realizar nuevas aportaciones al capital social a fin de hacer frente a la cuantía objeto de la condena.

Sin embargo, debe aclararse que la única alternativa coherente con el expuesto régimen de responsabilidad limitada para una cooperativa condenada por defectos constructivos, que hubiera entregado ya sus viviendas, anejos y locales y careciera de tesorería suficiente para hacer frente a la cuantía objeto de condena, sería la de solicitar la declaración de concurso de acreedores. Entrando en juego en este caso, todo lo expuesto anteriormente al respecto de ese escenario concreto.

Afortunadamente, la jurisprudencia mayoritaria no considera responsable a las cooperativas de viviendas por defectos constructivos, lo que contribuye a blindar el patrimonio de los socios más allá de las aportaciones ya realizadas y consolida el régimen de responsabilidad limitada.

\section{Bibliografía}

Bilbao Zorrozua, Ander: «El limite competencial del Consejo Rector frente a la Asamblea General de Socios en las Cooperativas de Vivienda». Gizarte Ekonomiaren Euskal Aldizkaria-Revista Vasca de Economía Social, n. ${ }^{\circ} 11,2014$, pp. 7-23.

Fajardo García, Gemma: "La responsabilidad del socio en la gestión económica de la cooperativa de viviendas desde la Jurisprudencia del Tribunal Supremo». Ciriec. Revista Jurídica de Economía Social y Cooperativa, n. ${ }^{\circ}$ 5, noviembre 1994, pp. 415-417.

Fajardo García, Gemma: "Cooperativas de viviendas. Constitución y funcionamiento", Ciriec, Valencia 2014.

Fernández García Lorenzana, I: «Responsabilidad del socio frente a las deudas sociales originadas como consecuencia de la actividad promocional en las sociedades cooperativas de viviendas", Revista Viviendas cooperativas (CONCOVI), n. ${ }^{\circ}$ 51, 2000, pp. 31-33. 
Gadea Soler, Enrique: "Alcance de la responsabilidad de los socios de una cooperativa de vivienda, anotación de la sentencia del Tribunal Supremo de 12 de diciembre de 2011», Revista Cooperativismo e economía social, n.o 37, Año 2014-2015, pp. 307-316.

Gondra Elgezabal, Gotzon: "Euskadiko Etxebizitza Kooperatibak (iruzkinak)», Gizarte Ekonomiaren Euskal Aldizkaria-Revista Vasca de Economía Social, n. ${ }^{\circ}$ 0, 2004, pp. 107-138.

Gondra Elgezabal, Gotzon:«Administratzaileen erantzukizuna Euskadiko Gizarte Ekonomiako enpresetan: Bereziki Kooperatiba Elkarteetan». Gizarte Ekonomia-

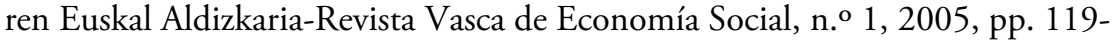
141.

Merino Hernández, Santiago: "Manual de Derecho de Sociedades Cooperativas", Universidad del País Vasco-Consejo Superior de Cooperativas de Euskadi, Vitoria-Gasteiz 2008, pp. 337-354.

Merino Hernández, Santiago: "Realidad de las cooperativas de viviendas en la Comunidad Autónoma del País Vasco", Gizarte Ekonomiaren Euskal AldizkariaRevista Vasca de Economía Social, n. ${ }^{\circ}$ 15, 2018, pp. 273-300.

Suso Vidal, José María: "El concurso de la sociedad cooperativa», Tratado de Derecho de Cooperativas, Tomo II, Tirant lo Blanch, Valencia 2013, pp. 15511574.

Villafañez Pérez, Itziar: "Cooperativa y concurso. Estudio de las relaciones jurídicas con sus socios» Marcial Pons, Madrid 2014. 